\title{
Zlib Compression
}

National Cancer Institute

\section{Source}

National Cancer Institute. zlib Compression. NCI Thesaurus. Code C80221.

An abstraction of the Deflate compression algorithm. 